\title{
Tercer puesto
}

\section{INVERSIÓN EXTRANJERA DIRECTA, CRECIMIENTO ECONÓMICO Y SPILLOVERS EN LOS PAÍSES MENOS DESARROLLADOS MIEMBROS DEL APEC}

\author{
Gabriela Cuadra Carrasco \\ PonTIFICIA UNIVERSIDAD CATÓliCA DEL PERÚ \\ David Florián Hoyle \\ PONTIFICIA UNIVERSIDAD CATÓLICA DEL PERÚ
}

\begin{abstract}
Resumen
El principal objetivo de esta investigación es entender el efecto de la inversión extranjera directa (IED) sobre el crecimiento de los países menos desarrollados miembros del APEC, considerando la transferencia y difusión tecnológica entre los países más desarrollados y los países menos desarrollados como la fuente más importante del desbordamiento del conocimiento. Con este fin se desarrolla un modelo de crecimiento endógeno que permite entender las relaciones subyacentes en la IED y sus consecuentes efectos. Luego, el modelo se implementa de manera empírica, mediante la estimación de una de las ecuaciones principales con la técnica de los Datos de Panel, donde se encuentra que, efectivamente, la IED causa un impacto positivo sobre la tasa de crecimiento de los países menos desarrollados y que este impacto depende, en gran medida, del stock de capital humano existente en el país receptor. Este efecto es significativo a partir de la década de los noventa, periodo durante el cual se implementan o se acentúan las reformas estructurales en muchos de los países comprendidos en el estudio.
\end{abstract}

\section{Introducción}

Se entiende por IED la forma de cooperación interfirma que no solamente involucra una participación significativa en las acciones de una firma doméstica o el control gerencial efectivo por parte de la firma extranjera, sino que también considera la inversión en activos tangibles e intangibles, incluyendo de este modo la inversión en infraestructura o acuerdos ta- les como franquicias, joint ventures y cooperación en investigación y desarrollo entre países y firmas (De Mello 1999).

Como tal, la IED es una fuente importante de acumulación de capital físico y de transferencia y difusión tecnológica para las economías en vías de desarrollo, ya que promueve el uso de nuevas tecnologías por parte de las empresas de la economía receptora de la inversión y, al mis- 
mo tiempo, genera incrementos en la productividad del factor trabajo, vía entrenamiento en actividades especializadas, y la adquisición de habilidades específicas.

Además, se suele argumentar que la IED es un vehículo de crecimiento económico; sin embargo, el impacto positivo dependerá en última instancia del alcance que tenga el efecto desbordamiento (spillovers) sobre las empresas domésticas y sobre la productividad de los factores del país receptor. Este hecho podría generar rendimientos crecientes en la producción agregada del país y mejorar los niveles de ingreso medio de las personas.

En particular, la hipótesis del trabajo considera que sí existe un efecto positivo de la IED en el crecimiento económico de los países menos desarrollados (PMD) miembros del APEC, el cual se debe a la transferencia y difusión tecnológica de los países más desarrollados hacia los menos desarrollados. Sin embargo, la magnitud de este efecto dependerá en gran medida de la capacidad de absorción de la tecnología por parte del país receptor, la cual se refleja en el stock de capital humano que los PMD posean.

El propósito de la presente investigación es determinar y cuantificar el impacto que ha tenido la IED en el crecimiento económico de los países menos desarrollados dentro del APEC y principalmente en el Perú. Asimismo, se pretende comprobar la existencia y el desarrollo del efecto de la difusión tecnológica (spillover) vía externalidades, que surge como consecuencia de la inversión extranjera directa en un contexto en que la relación entre ésta y el crecimiento es muy sensible a factores específicos de cada país. Se analizan las condiciones necesarias para que existan y/o se incrementen los efectos desbordamiento del conocimiento y transferencia tecnológica tomando en cuenta factores específicos no observables de cada país.

Para ello, se emplea un modelo de crecimiento endógeno - con dos países y tres sectores cada uno- que anula la condición de rendimientos decrecientes del capital mediante la inclusión de externalidades generadas a partir de la IED y sus correspondientes efectos spillovers y de transferencia tecnológica en los países receptores de la inversión (Barro y Sala- I Martin, 1995). En presencia de la IED, la función de producción agregada del país receptor está conformada tanto por la mano de obra, el stock de capital doméstico y el stock de capital extranjero. De este modo, la IED afecta al crecimiento directamente, a través del incremento del stock de capital físico a la vez que se acumula capital extranjero; e indirectamente, a través de la promoción del progreso técnico y sus efectos de desbordamiento (De Mello 1999: 143).

El presente documento consta de cinco secciones. En la segunda sección se presentan las tendencias mundiales en materia de flujos de IED y, en particular, su evolución en los países miembros del APEC. En la tercera sección se describe el marco teórico, poniendo énfasis en la estructura del modelo de crecimiento endógeno (un modelo de líder- seguidor). En la cuarta sección se presenta la implementación empírica de las relaciones de causalidad del modelo y un breve análisis de los resultados obtenidos. Finalmente, en la quinta sección se plantean algunas recomendaciones de política. 


\section{Tendencias mundiales}

\subsection{Marco general}

Una de las características más saltantes de la globalización económica ha sido la importancia que ha cobrado la inversión extranjera directa (IED) en el mundo. Durante los ochenta los flujos de IED permanecieron más o menos constantes; y a partir de los noventa, gracias a las reformas estructurales emprendidas en esa época, los flujos internacionales de IED se han incrementado en más de 10 veces, mientras que los flujos comerciales tan sólo se han duplicado. Así, según el World Investment Report, para el año 2000 la inversión extranjera directa se desarrolló con rapidez, aumentando con ello el peso de la producción internacional en la economía mundial. «La IED creció un $18 \%$ en el 2000, más deprisa que otros agregados económicos tales como la producción, la formación de capital y el comercio mundial y alcanzó la cifra récord de US\$ 1,3 miles de millones» (Unctad 2001).
Los países desarrollados continúan siendo el principal punto de destino de la IED, concentrando alrededor del $75 \%$ del total de las entradas mundiales. Ello, debido a que uno de los principales motores de expansión mundial es la corriente de inversiones generadas por las empresas transnacionales, así como también los procesos de fusiones y adquisiciones. De este modo, en el 2000, mientras las entradas de IED en los países desarrollados aumentaron $21 \%$ y rebasaron el billón de dólares, las entradas de IED en los países en desarrollo registraron un incremento de $8 \%$ respecto a 1999 , alcanzando tan sólo 240 mil millones de dólares. En cambio, la parte porcentual de estos países en las corrientes mundiales de IED, con relación a los desarrollados, disminuyó a 19\%, en comparación con un máximo de $41 \%$ en 1994.

Con relación a lo anterior, cabe mencionar que la denominada Tríada (Unión Europea, Japón y Estados Unidos) concentró en el 2000 cerca del $71 \%$ de las

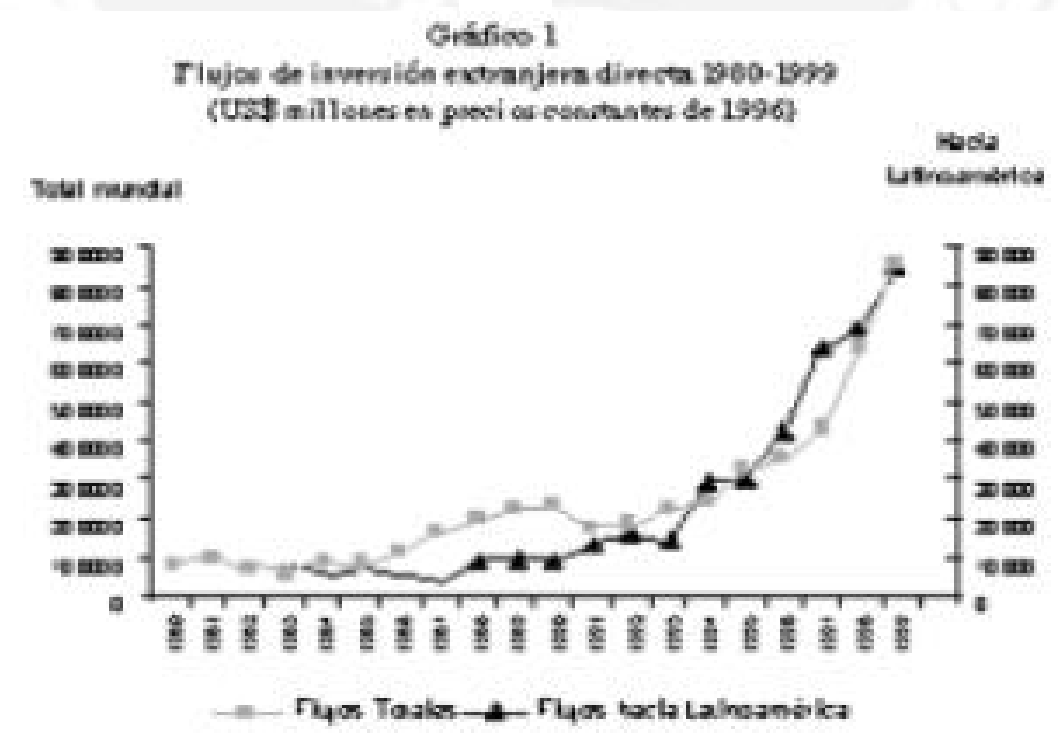

Año 8, n.․ 14, junio de 2003 
Gráfico 2

Distribución de las entradas de IED

(en US\$ miles de millones)

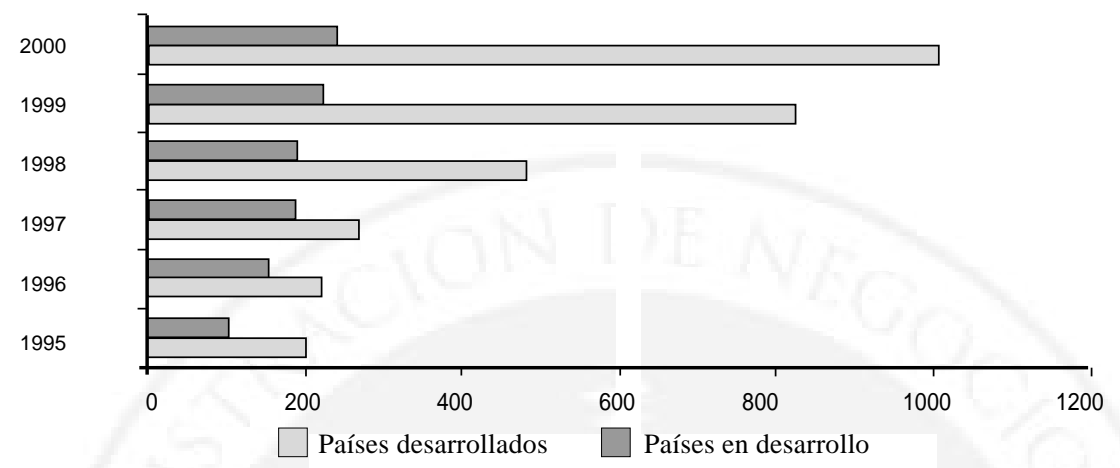

Fuente: Unctad 2001.

entradas de IED mundiales y el $81 \%$ de las salidas. Dentro del grupo de la Tríada, la Unión Europea (UE) ganó terreno a la vez como receptora y como proveedora de IED. El mayor flujo de entradas se debió al estímulo que supusieron los avances de la integración regional, mientras que los Estados Unidos y otros países de Europa Occidental continuaron siendo sus principales socios fuera de la región.

Como lo señala Stein (2001), en Latinoamérica y el Caribe (ver gráfico 1), a inicios de los noventas, tras aplicar medidas de desregulación y liberalización de los mercados, los flujos de IED se triplicaron y, como resultado de ello, Latinoamérica percibe hoy en día, alrededor del $10 \%$ de los flujos de IED del mundo. No obstante, para el 2000 dichas entradas disminuyeron en $22 \%$, alcanzando los 86 mil millones de dólares.

De otro lado, las entradas de IED hacia Europa Central y Oriental se incrementaron, llegando en el 2000 a US\$ 26 mil millones, y fueron explicadas por la gran cantidad de privatizaciones que se dieron en la región.

En África, se presentó un panorama distinto al registrado durante la década del noventa; en el 2000 la IED disminuyó de US\$ 10,5 mil millones a US\$ 9,1 mil millones, siendo los países más afectados Angola y Sudáfrica. Mientras tanto, en Asia se observó un incremento de las entradas de IED, alrededor de US\$ $143 \mathrm{mil}$ millones, lo cual se explica por el incremento en Asia Oriental; en particular, Hong Kong registró un repunte sin precedentes y pasó a ser el principal receptor de IED en Asia.

Por otro lado, es necesario hacer mención que a diferencia de otras fuentes de capital, como préstamos bancarios, bonos, portafolios de inversión, etc., la IED es la única fuente que canaliza el ahorro externo hacia el país receptor. Así, según información obtenida del World Investment Report (Unctad 2000), el porcentaje de IED mundial respecto a la inversión total mundial (medida como forma- 
Gráfico 3

Stock de IED entre la Tríada y los países en los cuales la IED de la Tríada predomina (1997)

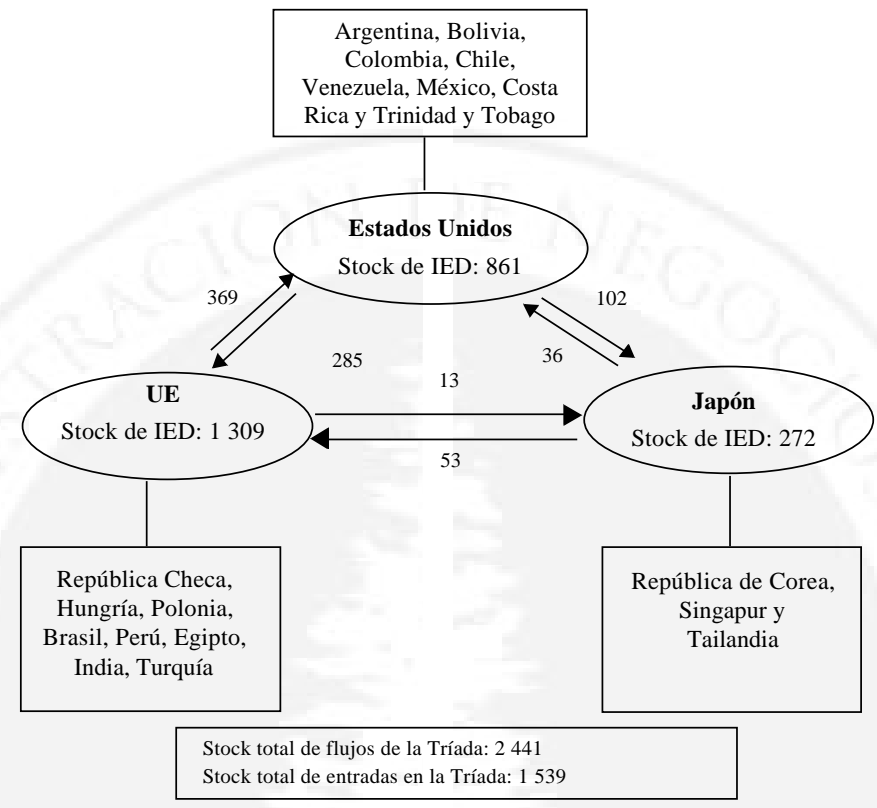

Fuente: Unctad 1999.

ción bruta de capital fijo) se ha incrementado en las últimas décadas, pasando de $4,1 \%$ entre los años 1988 y 1993 a $11,1 \%$ en 1998.

En particular, durante las tres décadas pasadas la importancia relativa de IED respecto a la inversión total se ha incrementado contundentemente, tanto en los países desarrollados como en los países en desarrollo. En los noventa, su importancia en los países en desarrollo y en transición se tornó más significativa que en los países desarrollados. Durante los años 1991 a 1997, el porcentaje que representó la IED respecto a la inversión total en los países desarrollados fue de $4,1 \%$, mientras en los países en desarrollo y en en transición fue aproximadamente de $7 \%$ y $7,5 \%$, respectivamente.

Dicho ratio se ha incrementado no sólo en los países, sino también a nivel de regiones y subregiones (con excepción del Este Asiático). Por ejemplo, según datos de la Unctad, el ratio en África, Latinoamérica, el Caribe, el Este Asiático y en el Sudeste Asiático se ha incrementado a niveles dos veces mayor a los del ochenta.

No obstante su rápido crecimiento, debemos señalar que la IED juega un modesto rol en la inversión doméstica para la gran parte de los países, ya que en alrededor del $65 \%$ de los países el ratio no excede el $10 \%$. 


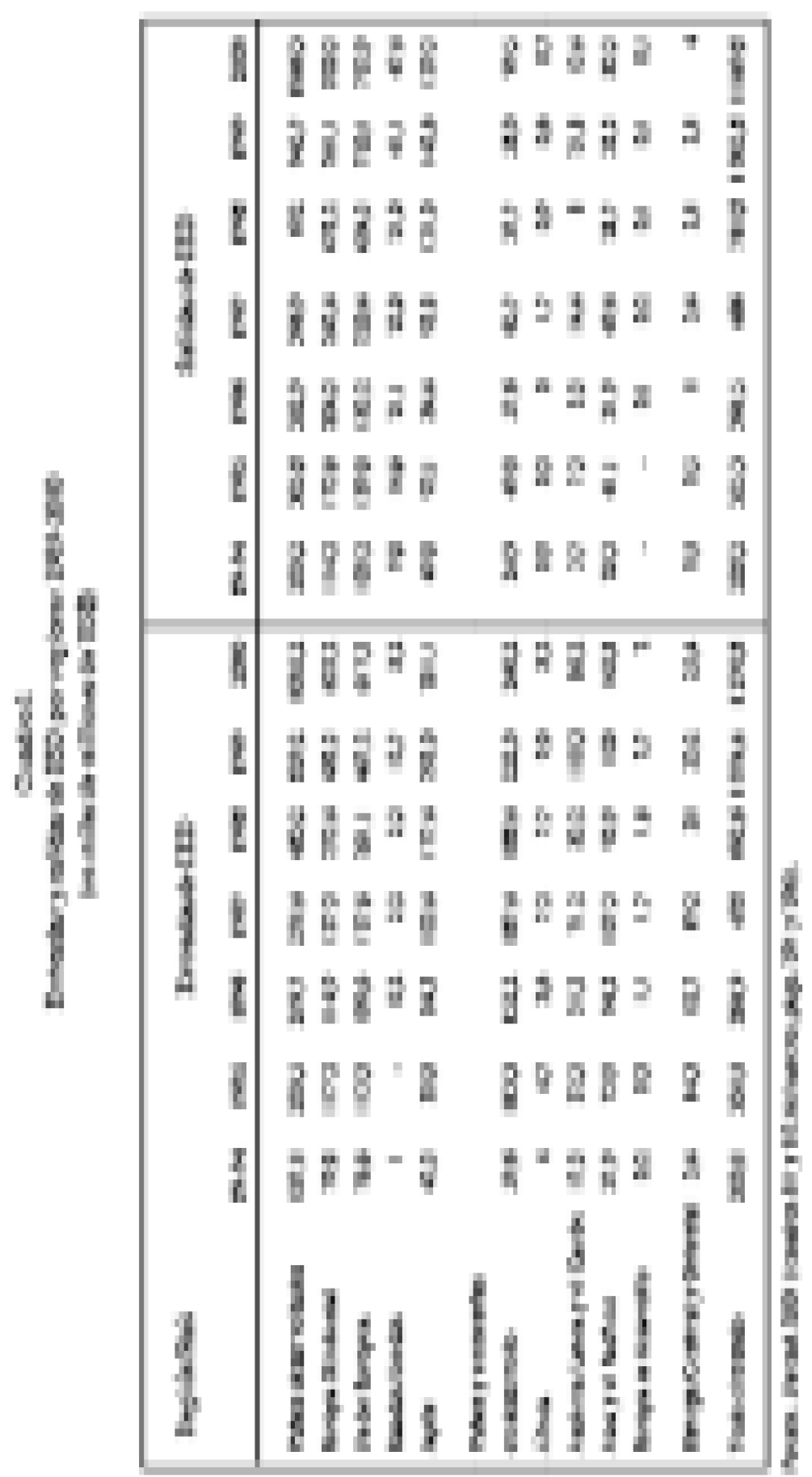




\subsection{Países miembros del APEC}

En el caso específico de los países miembros del APEC, la IED se ha mantenido más o menos constante durante la década, a excepción del periodo 1996-2000, lo cual se debió quizá a las consecuencias de la crisis asiática. En el 2000, las entradas de IED a los países del APEC alcanzaron la cifra de US\$ 513 mil millones, registrando un incremento de $13 \%$ respecto a 1999 .

No obstante, cabe resaltar que del total de flujos de IED mundial el porcentaje que se destina a dicha región es bastante significativo -más del 50\%-, debido a que dentro de los países miembros del Foro de Cooperación Asia Pacífico se encuentran Estados Unidos y Japón, países miembros de la denominada Tríada, que, como se mencionó anteriormente, concentra gran parte de las entradas y salidas de IED en el mundo.

Dentro de los proveedores netos de IED en dicha región están Estados Uni- dos, Taipei, Hong Kong, Japón y Corea. Además, debe señalarse que de los Nuevos Tigres Asiáticos, Singapur es el único receptor neto de IED, mientras que Corea del Sur, Taiwan y Hong Kong son proveedores netos de IED.

Para analizar la interdependencia de la IED en los países del APEC (ver anexo 1), se puede citar la información extraída de una investigación realizada anteriormente por el Comité Económico del APEC. En ésta se obtuvo que, entre los años 1993 y 1994, Estados Unidos comprendía alrededor de 31 a $33 \%$ de entradas de inversión extranjera directa proveniente del APEC, lo cual implica que las relaciones de Estados Unidos con Europa, Latinoamérica y otras partes del mundo son más importantes. En el otro extremo, Brunei y Papúa Nueva Guinea marcaron un máximo de $100 \%$, como reflejo de su pequeño tamaño y su posible relación con sus vecinos más cercanos.

Así, tanto para las entradas como para las salidas de IED desde o hacia el APEC,

Gráfico 4

Entradas de IED a las economías miembros de APEC (US\$ millones)

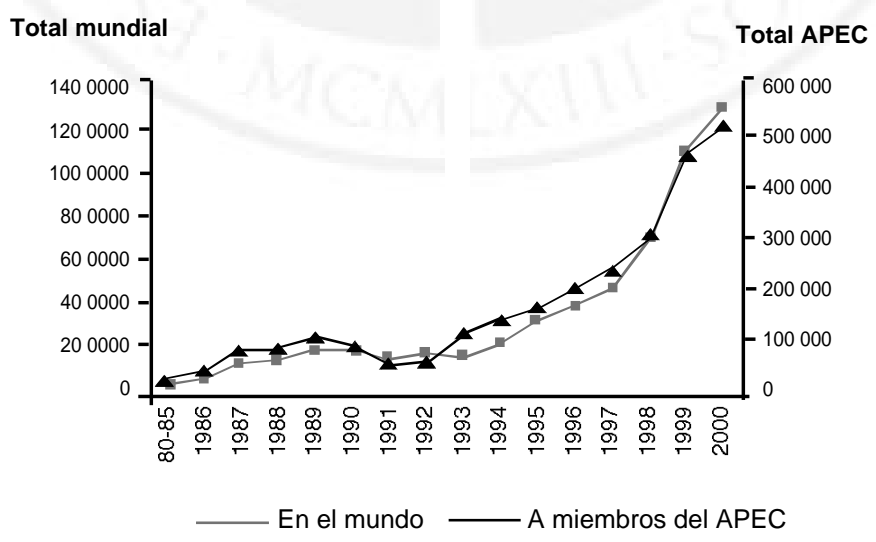

Año 8, n.ำ 14, junio de 2003 
Cuadro 2

Entradas de IED hacia los países miembros del APEC (mill. US\$)

\begin{tabular}{|lrrrr|}
\hline APEC & $80-85$ & $86-90$ & $91-95$ & $96-00$ \\
\hline Australia & 1968 & 6025 & 5941 & 7559 \\
Brunei & -1 & 0 & 8 & -29 \\
Canadá & -289 & 4417 & 5893 & 26444 \\
Chile & 212 & 462 & 1559 & 5477 \\
China & 718 & 2853 & 22535 & 41852 \\
Chinese Taipei & 185 & 987 & 957 & 879 \\
Hong Kong, China & 542 & 1945 & 3318 & 25129 \\
Indonesia & 227 & 599 & 2344 & 664 \\
Japón & 325 & 737 & 1437 & 5519 \\
Corea & 98 & 691 & 1016 & 6273 \\
Malasia & 1058 & 1126 & 4869 & 5117 \\
México & 1331 & 2617 & 7552 & 12086 \\
Nueva Zelanda & 277 & 792 & 2386 & 1787 \\
Papua Nueva Guinea & 98 & 139 & 214 & 149 \\
Filipinas & 35 & 493 & 1012 & 1349 \\
Singapur & 1330 & 3333 & 5823 & 8648 \\
Tailandia & 264 & 1188 & 1860 & 3410 \\
Estados Unidos & & & & \\
Perú & 154 & 3084 & 1948 & 1869 \\
Vietnam & 319 & 1936 & 1613 & 2334 \\
Entradas totales a las economías de APEC & 27120 & 81708 & 108677 & 344171 \\
Entradas totales en el mundo & 49831 & 155356 & 211343 & 780237 \\
Entradas totales a APEC / Entradas totales & & & & \\
al mundo & $54,4 \%$ & $54,2 \%$ & $50,6 \%$ & $46,1 \%$ \\
\hline
\end{tabular}

Fuente: World Investment Report, 1992, 1996, 1998 y 2001.

con relación al mundo todos los países miembros, a excepción de Estados Unidos, presentan un ratio de interdependencia mayor a $50 \%$, lo cual hace notar la creciente importancia que este foro está cobrando.

En el anexo 1 se muestra la importancia relativa de las economías del APEC como fuente de entradas de IED a los países del APEC en 1994. Ello refleja de hecho que Japón y Estados Unidos fueron los proveedores más importantes de la mayoría de economías del APEC. Estas economías están consideradas como las dos economías inversoras más importan- tes dentro de todas las economías que invierten en el APEC.

Las excepciones parecen ser relativas a la proximidad geográfica. Por ejemplo, Singapur es el segundo inversionista (luego de Japón) en Brunei, Indonesia y Malasia, mientras que Hong Kong fue el primero en China, Australia lo fue en Nueva Zelanda y Papúa Nueva Guinea. En Tailandia y Filipinas, los flujos de IED se derivan fundamentalmente de Japón y Estados Unidos.

Dentro de los miembros latinoamericanos, en Chile, el principal proveedor de 
inversión extranjera directa es Canadá, luego de Estados Unidos; mientras en México las entradas de IED provienen, sobre todo, de Estados Unidos, Japón y, en tercer lugar, Canadá.

\section{Marco teórico}

\subsection{Efectos positivos de la IED}

Hay muchos mecanismos a través de los cuales la IED puede generar efectos positivos en el crecimiento de los países de destino:

- Transferencia tecnológica (efecto directo). Se dice que la transferencia tecnológica -una de las principales fuentes de provisión de nueva tecnología en los países en desarrollo- es un efecto directo porque comprende la transferencia de bienes físicos y la transferencia de conocimiento tácito de la corporación transnacional a sus sucursales. De este modo se incrementa la producción agregada de la economía receptora mediante la combinación del capital físico (doméstico o extranjero) y el empleo. Entonces, la inversión extranjera directa afecta el crecimiento directamente, mediante el incremento del stock de capital de la economía receptora, produciendo la acumulación del capital.

En la actualidad, el conocimiento tácito se ha tornado más importante y comprende la adquisición de conocimientos nuevos y habilidades, tanto técnicas como organizacionales. El costo de adquisición puede ser sustancial y depende entre, otros factores, de la «distancia tecnológica» o diferencias en la especialización, etc. Aunque los beneficios son difíciles de medir, en el corto plazo éstos pueden generar incremento de productividad, innovación en los productos y menores costos de producción.

- Difusión tecnológica y spillovers (efecto indirecto). Se dice que hay un efecto indirecto porque la IED comprende el esparcimiento del conocimiento de las firmas extranjeras (sean las transnacionales o sus sucursales) hacia las firmas locales, las cuales inician un proceso de imitación o adaptación de los bienes intermedios, procesos productivos, estrategias de marketing y manejo gerencial de las transnacionales y, de este modo, se promueve el progreso tecnológico (De Mello 1999). Cabe resaltar que en este caso particular el conocimiento se torna disponible y puede ser usado por varias personas (en este caso firmas), sin que el uso de una impida o dificulte el uso a la otra; por ello se considera que el conocimiento será un bien de precio cero.

Como lo manifiestan Borensztein y otros (1998:123), la difusión tecnológica puede llevarse a cabo a través de diversos canales. La importación de productos con altos niveles tecnológicos, la adopción de tecnología extranjera y de capital humano son conductos importantes para la difusión internacional de tecnología.

$\mathrm{Al}$ respecto, algunos estudios como el mencionado han encontrado evidencias de que, para beneficiarse de la tecnología avanzada introducida por las firmas extranjeras, el país receptor tiene que ser capaz de absorber tal tecnología. 
Sin embargo, la aplicación de estas tecnologías más avanzadas también requiere la presencia de un nivel de capital humano mínimo del lado de los países receptores. Por lo tanto, el stock de capital humano en el país receptor limita la capacidad de absorción de un país en desarrollo (Borensztein y otros, 1998: 125).

Por ejemplo, como lo señala Yoo Soo Hong (2000) con relación a la fuerza laboral, en el caso de las economías o países más desarrollados del APEC, el porcentaje de «conocimiento en los trabajadores» es superior al 30\%. En el caso de los países latinoamericanos, dicho porcentaje varía entre 10 y $20 \%$, lo cual sugiere que todos los países miembros del APEC poseen cierto grado de capital humano y la capacidad de absorber tecnología.

\section{2. ¿Complementariedad o sustitu- ción?}

Asimismo, es necesario analizar si la IED complementa o desplaza la inversión doméstica; es decir, si hay complementariedad o sustitución entre la IED y la inversión doméstica. Es importante evaluar si la IED enfatiza la «destrucción creativa» a través de la sustitución con el fin de examinar la complementariedad entre la IED y la inversión doméstica, ya que esto afecta al crecimiento de la producción. Bajo complementariedad, las innovaciones pueden incorporarse como inversión extranjera y pueden incrementar en vez de reducir las rentas provenientes de viejas tecnologías.

Las fases de complementariedad y sustitución pueden alternarse en el ciclo de vida de la IED relacionada con las innovaciones. Como resultado, un ratio de cambio tecnológico se materializará en menor tiempo en bienes producidos con IED, lo que puede producir una mayor tasa de capital obsoleto o fragmentado. Esto puede afectar el crecimiento del producto vía el crecimiento del factor de productividad total, dependiendo del rango de tiempo de la inversión, de la depreciación rápida que reduce la acumulación del capital neto mientras se incrementa el crecimiento del factor de productividad total. Como resultado, en términos de contabilidad del crecimiento, el factor de acumulación de capital en presencia de IED podría dar paso a una mayor medida de crecimiento del factor de productividad total, particularmente si las transferencias tecnológicas y los spillovers de productividad abundan.

Con relación a este punto, siguiendo a De Mello (1997), se puede hacer una distinción entre los países en desarrollo (seguidores de la tecnología) y los países desarrollados (líderes tecnológicos). En los países en desarrollo la complementariedad entre la tecnología nueva y la tecnología vieja es predominante. La IED puede ser estimulada, en primer lugar, como un factor de acumulación y, por lo tanto, dar paso a una diversidad productiva basada en el crecimiento más rápido. Los beneficios de la IED pueden ser vistos esencialmente de manera cuantitativa, en el sentido de un crecimiento más rápido debido al factor acumulación, y pueden ser vistos como un mejor indicador del desarrollo global más que del mejor uso de los insumos productivos. En los países tecnológicamente más avanzados, la sustitución predomina y el aspecto cualitativo de la IED relacionada con el cambio tecnológico puede estar más vinculado con el hacedor de política. 


\subsection{Modelos de crecimiento endógeno y progreso técnico}

\subsubsection{Introducción}

La característica principal de los modelos de crecimiento endógeno es la eliminación de los rendimientos decrecientes del factor productivo acumulado (capital en un sentido amplio), mediante la inclusión de rendimientos constantes o crecientes a escala, externalidades o efectos desbordamiento (spillovers), situaciones de aprender haciendo (learning by doing), inversiones en capital humano o progreso técnico endógeno. Estos supuestos permiten sostener el carácter endógeno del crecimiento económico y explicar de este modo la existencia de tasas de crecimiento sostenidas, variables y diferentes entre países.

En esta sección se presenta un modelo de crecimiento endógeno que anula la condición de rendimientos decrecientes del capital mediante la modelización de los determinantes del progreso técnico, es decir, mediante la inclusión de un sector de empresas dedicadas a la investigación y desarrollo (I+D).

El supuesto fundamental en este tipo de modelos es que no existen rendimientos decrecientes en la producción de bienes de capital, lo que genera una tasa de crecimiento endógena, es decir, se determina dentro del propio modelo. Así, la tasa de crecimiento del producto por trabajador dependerá, exclusivamente, de las decisiones de los individuos y no de variables exógenas, como es el caso de los modelos de crecimiento neoclásico.

En el presente trabajo, y al igual que Romer (1990), se supone que la endoge- nización del progreso técnico toma la forma de un incremento en el número de bienes de capital disponibles como factores de producción ${ }^{1}$. Como señala Sala-i-Martin (2000), esta forma de tratar con la endogenización del progreso técnico supone que los países más desarrollados utilizan mayor variedad de factores en la producción de bienes finales que los países menos desarrollados. Un incremento en el número de variedades de bienes de capital requiere de una innovación tecnológica por parte de las empresas productoras de bienes finales; de este modo adaptan sus procesos productivos a los nuevos bienes intermedios.

\subsubsection{La difusión tecnológica: un modelo líder-seguidor ${ }^{2}$}

En el mundo actual hay unos pocos países donde la inversión en $\mathrm{I}+\mathrm{D}$ parece ser importante; el resto de países se limita a esperar que los líderes tecnológicos inventen nuevos productos, bienes intermedios, nuevos procesos productivos o mejoren la calidad de los productos existentes, para después imitarlos u observar cómo se difunden a través de las corporaciones transnacionales.

Como se mencionó en la sección anterior, la transferencia tecnológica juega un rol undamental en el proceso de crecimiento económico; en este contexto, las empresas transnacionales son consideradas la principal fuente directa de tecnología para los países en desarrollo.

1. Un segundo enfoque considera que el progreso técnico se verifica a través de un aumento en la calidad de un número limitado de productos.

2. Esta sección se basa en Barro y Sala-i-Martin (1995), Sala-i-Martin (2000) y Boreinztein y otros (1998). 
En el modelo que se presenta a continuación se supone que existen sólo dos países: el primero de ellos es un líder tecnológico, es decir, representa una economía desarrollada que cuenta con un gran sector dedicado a la investigación y desarrollo, mientras que el segundo representa una economía en desarrollo, es decir, es un país que en el tema de I+D se dedica a imitar y adaptar tecnología proveniente de firmas extranjeras que han emprendido procesos de inversión extranjera, exportando de esta manera bienes de capital.

En cada uno de estos países existen tres tipos de agentes:

- Las empresas dedicadas a investigación y desarrollo, que son empresas productoras de bienes intermedios o de capital. Estas firmas invierten una cierta cantidad de recursos para crear nuevos productos y una vez que los han desarrollado obtienen una patente que les concede un monopolio perpetuo para su producción y alquiler.

- Los productores de bienes finales, que emplean trabajo y los bienes de capital producidos por las empresas dedicadas a I+D y, por lo tanto, rentan de ellas.

- Los consumidores, que eligen la cantidad que desean consumir y ahorrar para maximizar una función de utilidad habitual sujeta a una restricción intertemporal.
A. El país líder
a) Los productores de bienes finales

Los productores de bienes finales tienen la siguiente función de producción:

$$
Y_{1}=A_{1} L_{1}^{1-\alpha}\left(\sum_{t=1}^{N} x_{1 t}^{\alpha}\right)
$$

Donde A es un parámetro tecnológico, $\mathrm{Y}_{1 \mathrm{t}}$ es el producto, $\mathrm{L}_{1 \mathrm{t}}$ es capital humano $\mathrm{y} \mathrm{x}_{1 \mathrm{t}}$ es el empleo del t-ésimo bien intermedio o de capital.

Como es usual en la literatura, los productores de bienes finales maximizan el valor presente de su función de beneficios. Se supone que el mercado de mano de obra es competitivo y que además alquilan cada una de las variedades de bienes intermedios al precio de R. Por lo tanto, el problema que resuelven estas empresas es:

$$
\begin{aligned}
& \operatorname{Max} \int_{0}^{\infty} e^{-r t}\left(Y_{1}-w L_{1}-\sum_{t=1}^{N} R_{1} x_{1 t}\right) d t \\
& \text { s.a. } Y_{1}=A_{1} L_{1}^{1-\alpha}\left(\sum_{t=1}^{N} x_{1 t}^{\alpha}\right)
\end{aligned}
$$

Las condiciones de primer orden imponen la igualdad entre los productos marginales y los precios de los factores:

$$
\begin{aligned}
& R_{1}=\alpha A_{1}\left(x_{1 t}\right)^{\alpha-1}\left(L_{1}\right)^{1-\alpha} \\
& W_{1}=(1-\alpha) A_{1}\left(\sum_{t=1}^{\sum} x_{1 t}^{\alpha}\right) L_{1}
\end{aligned}
$$

De la primera condición, se obtiene $l a$ demanda por bienes de capital:

$$
x_{1 t}=L_{1}\left(A_{1} \alpha / R_{1}\right)^{1 / 1-\alpha}
$$

\section{b) Las empresas de I+D: Investiga- ción y Desarrollo}

Las empresas de $\mathrm{I}+\mathrm{D}$ deben invertir recursos para poder crear nuevos bienes de 
capital; se asumirá que el costo de invertir en crear una nueva variedad de estos bienes es constante e igual a $\eta$. Por otro lado, el producto se alquila a una tasa $\mathrm{R}_{\mathrm{t}} \mathrm{a}$ los productores de bienes finales; además, la sociedad otorga a estas empresas un monopolio perpetuo en forma de derechos de propiedad sobre los bienes que desarrollan, como un incentivo para dedicarse a esta actividad.

Cabe resaltar que estas empresas no retienen estos derechos de propiedad cuando exportan bienes intermedios al país menos desarrollado. Se hace este supuesto como una forma de modelar los efectos indirectos de la IED, es decir, el efecto desbordamiento y de difusión tecnológica sobre la economía receptora, que como se sabe se complementa con los efectos directos de transferencia tecnológica por medio de las sucursales de las corporaciones transnacionales que operan en el país menos desarrollado.

Al igual que los productores de bienes finales, las empresas de I+D maximizan beneficios; se supone que el costo marginal de producir una unidad adicional de $\mathrm{X}_{1 \mathrm{t}}$ es constante e igual a 1 . El problema por resolver para este tipo de empresas puede representarse de la siguiente manera:

$$
\operatorname{Max} \int_{0}^{\infty}\left(R_{1}-1\right) x_{1 t} e^{-r t} d t-\eta
$$

s.a. $R_{1}=\alpha A_{1}\left(x_{1 t}\right)^{\alpha-1}\left(L_{1}\right)^{1-\alpha}$

Al resolver este problema se obtiene el nivel de producción de equilibrio para cada variedad de bienes de capital:

$$
x_{1 t}=L_{1} A_{1}^{1 / 1-\alpha} \alpha^{2 / 1-\alpha}
$$

Igualando la demanda por bienes de capital (3) con el nivel de producción de equilibrio de éstos (4), se obtiene una expresión para la tasa de alquiler:

$$
\mathrm{R}_{1}=1 / \alpha
$$

Por último, se supone libre entrada en las actividades de $\mathrm{I}+\mathrm{D}$, lo que implica que el costo de invertir en esta actividad debe igualar al valor presente de todos los beneficios futuros, es decir,

$$
\int_{0}^{\infty}\left(R_{1}-1\right) x_{1 t} e^{-r t} d t=\eta
$$

Resolviendo se obtiene:

$$
r=\frac{\psi A_{1}^{1 /(1-\alpha)} L_{1}}{\eta}
$$

donde $\psi=[(1-\alpha) / \alpha] * \alpha^{2} /(1-\alpha)$.

\section{c) Los consumidores}

Para cerrar el modelo, es preciso especificar el proceso de acumulación de capital, el cual se determina mediante la trayectoria de ahorro óptimo que viene dada por la ecuación de Euler.

Se asume que las familias maximizan una función de utilidad intertemporal estándar:

$$
U_{1 t}=\int_{0}^{\infty} \frac{C_{t}^{1-\sigma}}{1-\sigma} e^{\rho t} \mathrm{dt}
$$

donde $\mathrm{C}$ denota consumo del bien final.

La ecuación de Euler, que determina la trayectoria de consumo óptimo es: 


$$
\frac{\dot{C}}{C}=\frac{1}{\sigma}(r-\rho)
$$

Sustituyendo la ecuación 5 en la 6 , se obtiene:

$$
\gamma=\frac{C}{C} \cdot \cdot=\frac{1}{\sigma}\left(\frac{\psi \mathrm{A}_{1}^{1 /(1-\alpha)} L_{1}}{\eta}-\rho\right)
$$

Es fácil demostrar que en este tipo de modelos la tasa de crecimiento del consumo es igual que la tasa de crecimiento del producto. Por último, cabe destacar que la tasa de crecimiento está inversamente relacionada con el costo de las actividades de I+D, y de forma positiva con el tamaño de la población de la economía.

\section{B. El país seguidor}

\section{a) Los productores de bienes finales}

La función de producción de una firma representativa productora de bienes finales en el país 2 es:

$$
Y_{2}=A_{2} L_{2}^{1-\alpha}\left(\sum_{t=1}^{N} x_{2 t}^{\alpha}\right)
$$

donde $\mathrm{A}_{2}$ es un parámetro tecnológico, $\mathrm{Y}_{1 \mathrm{t}}$ es el producto, $\mathrm{L}_{1 \mathrm{t}}$ es el capital humano y $\mathrm{x}_{1 \mathrm{t}}$ es el empleo del t-ésimo bien intermedio o bien de capital.

Como se menciona más adelante, $\mathrm{N}$ está compuesto por la producción de bienes intermedios o de capital por parte de firmas domésticas (n) y por firmas extranjeras que operan en el país seguidor como sucursales de las corporaciones multinacionales $(\mathrm{n} *)$.

Al igual que en el país líder, los productores de bienes finales maximizan el valor presente de su función de beneficios. Como en el caso anterior, se supone que el mercado de mano de obra es competitivo y que además alquilan de las empresas I+D cada una de las variedades de bienes intermedios al precio de $\mathrm{R}_{2}$. Por lo tanto, el problema que resuelven estas empresas es:

$$
\begin{aligned}
& \operatorname{Max} \int_{0}^{\infty} e^{-r t}\left(Y_{2}-w L_{2}-\sum_{t=1}^{N} R_{2} x_{2 t}\right) d t \\
& \text { s.a. } Y_{2}=A_{2} L_{2}^{1-\alpha}\left(\sum_{t=1}^{N} x_{2 t}^{\alpha}\right)
\end{aligned}
$$

Las condiciones de primer orden imponen la igualdad entre los productos marginales y los precios de los factores:

$$
\begin{aligned}
& R_{2}=\alpha A_{2}\left(x_{2 t}\right)^{\alpha-1}\left(L_{2}\right)^{1-\alpha} \\
& W_{2}=(1-\alpha) A_{2}\left(\sum_{t=1}^{N} x_{2 t}^{\alpha}\right) L_{2}
\end{aligned}
$$

Utilizando la primera ecuación obtenemos la demanda por bienes de capital del país 2:

$$
x_{2 t}=\mathrm{L}_{2} \frac{\mathrm{A}_{2} \alpha^{1(1-\alpha)}}{R_{2}}
$$

Según esta función, la demanda de $\mathrm{x}_{2 \mathrm{t}}$ está negativamente relacionada con el precio unitario de alquiler.

\section{b) Las empresas de $I+D$}

Para este tipo de firmas un incremento en el número de variedades de capital requiere de la adaptación o imitación de la tecnología disponible en el país líder; se asume que este proceso de adaptación tecnológica es costoso y requiere de un costo fijo de instalación que se denominará F. Además, se supone que las sucursales de las corporaciones transnacionales no incurren en dicho costo. 
Se asume que $\mathrm{F}$ depende de manera inversa del ratio entre número de empresas extranjeras que operan en la economía receptora y el total de empresas $(\mathrm{n} * / \mathrm{N})$. Por lo tanto, si el ratio aumenta, significa que se incrementa el número de sucursales de las corporaciones transnacionales en el país receptor, y que ahora es más fácil para las empresas domésticas imitar o adaptar los nuevos bienes de capital extranjeros a sus procesos de producción. Es decir, existen mejores condiciones para el desbordamiento del conocimiento.

Al igual que sus análogos del primer mundo, estas empresas maximizan beneficios.

Se supone que el costo marginal de producir una unidad adicional de $\mathrm{x}_{1 \mathrm{y}}$ es constante e igual a 1. Por lo tanto, el problema por resolver para este tipo de empresa es:

$\operatorname{Max} \int_{0}^{\infty}\left(R_{2}-1\right) x_{2 t} e^{-r t} d t-\mathrm{F}\left(\mathrm{n}^{*} / \mathrm{N}\right)$

s.a. $R_{2}=\alpha A_{2}\left(x_{2 t}\right)^{\alpha-1}\left(L_{2}\right)^{1-\alpha}$

Como es de suponer, al resolver este problema se obtiene el nivel de producción de equilibrio para cada variedad de bienes de capital:

$$
X_{2 t}=L_{2} A_{2}^{1 / 1-\alpha} \alpha^{2 / 1-\alpha}
$$

Igualando la ecuación anterior a la demanda por bienes de capital se obtiene una expresión para la tasa de alquiler:

$$
\mathrm{R}_{2}=1 / \alpha
$$

Al igual que en el país anterior, se supone libre entrada en las actividades de I+D, lo que implica que el costo de imitar o de adaptar la tecnología disponible en el país líder debe igualar al valor presente de todos los beneficios futuros. Es decir:

$$
\int_{0}^{\infty}\left(R_{2}-1\right) x_{2 t} e^{-r t} d t=\mathrm{F}\left(\mathrm{n}^{\star} / \mathrm{N}\right)
$$

Resolviendo se obtiene:

$$
r=\frac{\psi A_{1}^{1 /(1-\alpha)} L_{1}}{F}
$$

donde $\psi=[(1-\alpha) / \alpha] * \alpha^{2} /(1-\alpha)$.

c) Los consumidores

Asumimos que los consumidores poseen la misma función de utilidad que los consumidores del país líder y que se enfrentan al mismo problema de optimización intertemporal, por lo que la condición de primer orden es:

$$
\frac{\dot{C}}{C}=\frac{1}{\sigma}(r-\rho)
$$

Sustituyendo la ecuación 10 en la 11 , se obtiene la tasa de crecimiento de la economía:

$$
\gamma=\frac{C}{C} \cdot \cdot=\frac{1}{\sigma}\left(\frac{\psi \mathrm{A}_{1}^{1 /(1-\alpha)} L_{2}}{F\left(\frac{n^{*}}{N}\right)}\right)
$$

Esta ecuación indica que la IED, la cual se mide por el número de bienes de capital producidos por firmas extranjeras $(n * / N)$, se relaciona de manera directa con la tasa de crecimiento de la economía. Como se mencionó anteriormente, mientras más alto sea el ratio $(n * / N)$, más bajo será el costo de imitar o adaptar los procesos de producción existentes a los nuevos bienes de capital introducidos en el país líder. 


\section{Implementación empírica y conclusiones}

\subsection{Los datos}

La fuente principal para las series de IED es el World Investment Report, publicado por la Unctad. Para el stock de capital humano se utilizó el número de personas por encima de los 15 años de edad que terminaron la educación secundaria, y que es construido por Barro y Lee (2000). Los datos para el producto bruto interno (PBI), la formación de capital bruto y otras variables utilizadas en el análisis empírico se obtuvieron de International Financial Statistics, del Fondo Monetario Internacional (FMI). Hay que señalar que se utiliza un periodo de estimación de dos décadas, desde 1980 hasta el 2000, para todas las variables.

Como países menos desarrollados del Foro de Cooperación Asia Pacífico se ha considerado ocho países miembros: Perú, Malasia, Indonesia, Tailandia, Chile, México, Papúa Nueva Guinea y Filipinas. Vietnam y Rusia no fueron considerados debido a la falta de datos o a la calidad de los mismos para el periodo de estudio y porque ambos pertenecieron a los llamados países socialistas; por lo tanto, es de esperar que no recibieran IED por parte de los países capitalistas de ese entonces.

Para implementar empíricamente el modelo, se utiliza una aproximación lineal de los determinantes del producto para el país seguidor, es decir, de la ecuación (12). Para este fin se utiliza la siguiente especificación:

$$
\begin{aligned}
& g_{\text {it }}=c_{0}+c_{1} I E D_{i t}+c_{2} H+ \\
& \text { c3 }\left(I E D^{*} H\right)_{i t}+c_{4} A_{i t}
\end{aligned}
$$

donde el subíndice i hace referencia al país, mientras que el subíndice t, a los años considerados en la estimación. Además, IED se refiere a la inversión extranjera directa, $\mathrm{H}$ indica el stock de capital humano y A es un conjunto de otras variables que se utilizarán en la estimación. Hay que mencionar que la variable IED cumple el mismo papel que el ratio $n * / \mathrm{N}$.

La ecuación anterior se estimará mediante un modelo de datos de panel, que, por lo tanto, controla los factores específicos no observables de cada país. Entre estos factores específicos destacan el marco institucional, el riesgo político, la estabilidad macroeconómica, la política comercial, etc., que determinan el atractivo del país para la inversión extranjera y el deseo del inversionista extranjero de invertir en transferencia tecnológica.

Se puede afirmar que la principal ventaja de utilizar modelos de datos de panel radica en permitir diferencias en la función de producción agregada entre los diferentes países que conforman el estudio (Islam 1995). De este modo se identifican los efectos individuales pertenecientes a cada país y que pueden interpretarse como diferencias no observables en tecnología, capital humano, factores socioeconómicos, así como los requisitos institucionales y económicos necesarios para atraer y desarrollar la transferencia de conocimiento de la IED de cada país en estudio.

\subsection{Resultados y conclusiones}

En primer lugar, se debe mencionar que se realizó el Test de Haussman para determinar si el modelo de datos de panel se estima como uno de efectos fijos o como uno de efectos aleatorios; los resultados 
del test muestran que el modelo correcto es el de efectos fijos.

Los resultados de la estimación de efectos fijos incluyendo la muestra completa (1980-2000) indican principalmente que la IED tiene un efecto positivo y significativo sobre el crecimiento económico de los países menos desarrollados miembros del APEC; es decir, la IED se relaciona de manera directa con la tasa de crecimiento del PBI de dicho grupo de países, los cuales se asemejan al país seguidor presentado en el modelo teórico de la sección anterior.

Como se puede observar en la tabla de resultados 1 , en las tres estimaciones presentadas el coeficiente que corresponde a la IED es positivo y significativo indicando el efecto positivo de ésta en el crecimiento de los países seguidores de tec- nología. Por otro lado, el coeficiente que corresponde a la inversión total como ratio del PBI también es positivo y significativo en las tres estimaciones, como era de esperarse.

Sin embargo, la magnitud del efecto de la IED depende en gran medida del stock de capital humano existente en el país receptor. Así, en países que cuentan con niveles bajos de stock de capital humano, el efecto de la IED es menor que en países con un alto nivel de capital humano. En la estimación (1.2) se incluyen como variables independientes el capital humano y la IED para comprobar si es que estas variables influyen en el crecimiento económico de manera individual. Como se puede observar, los coeficientes de las dos variables son positivos, significativos y muy similares a los obtenidos en la estimación (1.1).

Resultados 1

Panel de efectos fijos: Crecimiento del PBI

(1980-2000)

\begin{tabular}{|lrrr|}
\hline & $\mathbf{( 1 . 1 )}$ & $\mathbf{( 1 . 2 )}$ & $\mathbf{( 1 . 3 )}$ \\
\hline $\begin{array}{l}\text { Variables } \\
\text { Independientes }\end{array}$ & & & \\
\hline \multirow{2}{*}{ IED } & & & \\
& 4,710984 & 4,324538 & 2,306506 \\
Inversión/PBI & $(0,0000)$ & $(0,0000)$ & $(0,0002)$ \\
& 2,593631 & 2,164394 & 2,203448 \\
Capital humano & $(0,0000)$ & $(0,0000)$ & $(0,0000)$ \\
& & 0,019636 & 0,018191 \\
IED*Capital humano & & $(0,0000)$ & $(0,0000)$ \\
& & & 0,0000187 \\
& & & $(0,0011)$ \\
\hline R2 & 0,9043 & 0,9319 & 0,9357 \\
\hline
\end{tabular}


En la ecuación (1.3) se incluyó como variable independiente el producto entre la IED y el capital humano como aproximación a la interacción existente entre estas dos variables. Como se puede observar, la inclusión de esta variable mejora el desempeño de la estimación en términos del coeficiente de determinación, pero reduce significativamente el efecto individual de la IED sobre la tasa de crecimiento del producto. Esto confirmaría la complementariedad existente entre la IED y el stock de capital humano en el país receptor, es decir, que el efecto final de la IED sobre el crecimiento de los países menos desarrollados depende significativamente del stock de capital humano en la economía receptora o, lo que es lo mismo, de la capacidad que un país tenga de absorber tecnología extranjera y adaptarla a sus procesos productivos.
En último lugar, se optó por dividir la muestra en dos subperiodos: 1980-1992 y 1992-2000, para reflejar de este modo el quiebre en la tendencia de los flujos de IED en el mundo (gráfico 1) entre las dos décadas que abarca el estudio. Como era de esperarse y como se muestra en la tabla de resultados 2 y 3 , el efecto de la IED en el crecimiento de los países menos desarrollados se reduce considerablemente en el periodo 1980-1992.

Cabe resaltar que en este periodo los coeficientes correspondientes a la IED no son estadísticamente significativos, por lo que se puede afirmar que la IED no tuvo un rol fundamental como determinante del crecimiento económico para este grupo de países durante los ochenta. Por el contrario y como se puede observar en la tabla de resultados número 3 , los coeficientes

Resultados 2

Panel de efectos fijos: Crecimiento del PBI (1980-1992)

\begin{tabular}{|lrrr|}
\hline \multicolumn{1}{|c|}{$(\mathbf{2 . 1})$} & $\mathbf{( 2 . 2 )}$ & $\mathbf{( 2 . 3 )}$ \\
\hline $\begin{array}{l}\text { Variables } \\
\text { Independientes }\end{array}$ & & & \\
\hline IED & 0,382026 & 0,478463 & 0,095674 \\
& $(0,6683)$ & $(0,5588)$ & $(0,9285)$ \\
Inversión/PBI & 2,192745 & 2,051702 & $\begin{array}{r}2,053032 \\
(0,0000)\end{array}$ \\
& & $(0,0000)$ & $(0,0000)$ \\
Capital humano & & 0,008810 & 0,006742 \\
& & $(0,0000)$ & $(0,0915)$ \\
IED* Capital humano & & & 0,000040 \\
& & & $(0,6077)$ \\
\hline R2 & 0,9679 & 0,9783 & 0,9786 \\
\hline
\end{tabular}


Resultados 3

Panel de efectos fijos: Crecimiento del PBI (1992-2000)

\begin{tabular}{|c|c|c|c|}
\hline & (3.1) & (3.2) & $(\mathbf{3 . 3})$ \\
\hline $\begin{array}{l}\text { Variables } \\
\text { Independientes }\end{array}$ & & & \\
\hline IED & $\begin{array}{r}2,312241 \\
(0,0041)\end{array}$ & $\begin{array}{r}2,128966 \\
(0,0038)\end{array}$ & $\begin{array}{r}1,274593 \\
(0,0582)\end{array}$ \\
\hline Inversión/PBI & $\begin{array}{r}1,982678 \\
(0,0000)\end{array}$ & $\begin{array}{r}1,808157 \\
(0,0000)\end{array}$ & $\begin{array}{r}1,768380 \\
(0,0000)\end{array}$ \\
\hline Capital humano & & $\begin{array}{r}0,032346 \\
(0,0000)\end{array}$ & $\begin{array}{r}0,032488 \\
(0,0000)\end{array}$ \\
\hline IED* Capital humano & & & $\begin{array}{r}0,000160 \\
(0,0966)\end{array}$ \\
\hline R2 & 0,9078 & 0,9278 & 0,9511 \\
\hline
\end{tabular}

correspondientes a la IED son positivos, significativos y mayores que los correspondientes al periodo 1980-1992. Es decir, durante la mayor parte de los noventa la IED tuvo un rol fundamental en el crecimiento de los países menos desarrollados miembros del APEC, debido principalmente a las reformas estructurales aplicadas en la mayoría de países en vías de desarrollo en esa década y que incluían, entre otras, la desregulación y liberalización de los mercados, así como el establecimiento de marcos institucionales que protegen los derechos de propiedad.

\subsection{Análisis de los efectos fijos}

Siguiendo a De Mello $(1997,1999)$ y a Nazrul (1995) se interpretan los efectos fijos que han sido estimados en el modelo de Datos de Panel, como las diferencias no observables entre países o los factores específicos a cada país que influyen en el crecimiento económico, así como también en la determinación de los flujos de IED hacia cada país.

Por lo tanto, se considerará que los efectos fijos reflejan los requisitos institucionales que debe tener un país para atraer la IED. Entre estos requisitos institucionales se encuentran: el grado de estabilidad política, el grado de intervención del gobierno en la economía, la existencia de derechos de propiedad que determinen los derechos legales que protejan a las firmas extranjeras de actos arbitrarios de expropiación, los procedimientos burocráticos, acuerdos internacionales de comercio e inversión, el grado de apertura de la economía y una adecuada infraestructura pública.

Como se puede observar en el gráfico 5 , existe una relación directa entre los efectos fijos y los flujos de IED hacia los países receptores. México es un caso especial, debido a que es un país geográfi- 
Gráfico 5

Efectos fijos 1980-2000

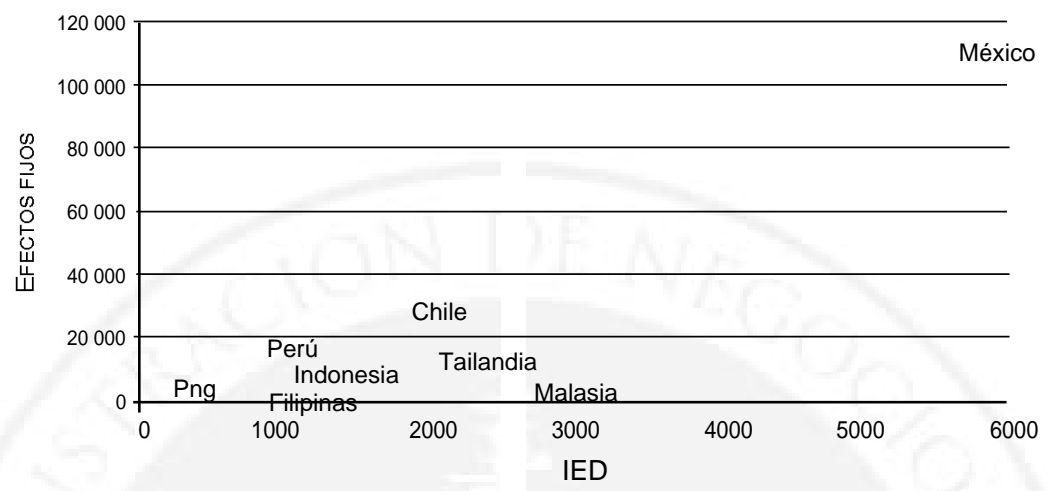

camente cercano a Estados Unidos y que a partir de 1995 es miembro del Tratado de Libre Comercio de América del Norte (NAFTA); además, la fuente principal de IED hacia México es Estados Unidos. Los demás países poseen para el periodo completo (1980-2000) efectos fijos similares, aunque se encuentra mayor dispersión en éstos que en los observados en el periodo 1992-2000.

Al parecer, cuando se analizan los efectos para el periodo que comprende sólo la década de los noventa se encuentra una relación directa mucho más clara entre los efectos fijos y los flujos de IED, y a la vez una menor dispersión entre éstos. Una posible interpretación de este resultado es el efecto que trajo consigo la aplicación de las reformas estructurales emprendidas en la década de los noventa, en términos de nuevos flujos de IED hacia los países menos desarrollados.

Por último, y como se puede observar en el siguiente gráfico, durante los ochenta los niveles de IED hacia los países menos desarrollados miembros del APEC fueron menores que los montos de IED registrada en la década de los noventa. Asimismo los efectos fijos estimados para este periodo reflejan una mayor dispersión que los anteriores, debido a que sólo algunos de estos países empezaban su ciclo de reformas.

\section{Recomendaciones de política}

Cabe resaltar que este trabajo no ha buscado entender cuáles son los determinantes de la IED; ha buscado, más bien, entender los efectos de la IED en el crecimiento de los PMD. Sin embargo, una vez entendidos estos efectos y por motivos de recomendaciones de políticas, es conveniente estudiar algunos de los principales determinantes de la IED, los cuales son requisitos institucionales que debe cumplir el país receptor. Entre éstos se encuentran el grado de estabilidad política y el grado de intervención del gobierno en la economía, la existencia de derechos de propiedad que determinen los derechos legales que protejan a las empresas extranjeras de actos arbitrarios de expropiación, ya sea por motivos políticos u otros. 


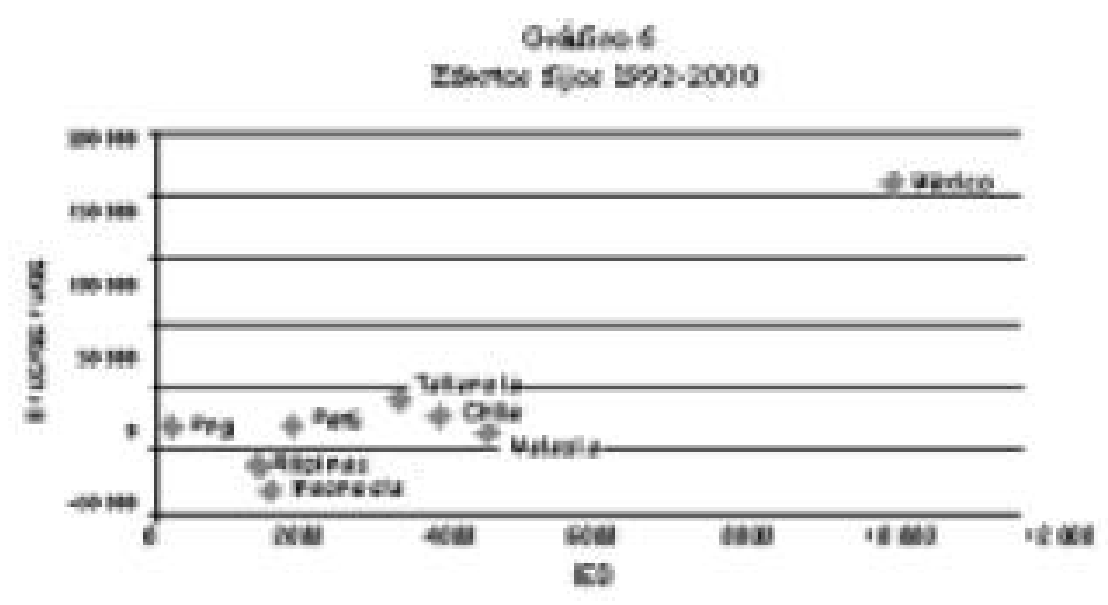

Brifis 7

Phat tips kip bit

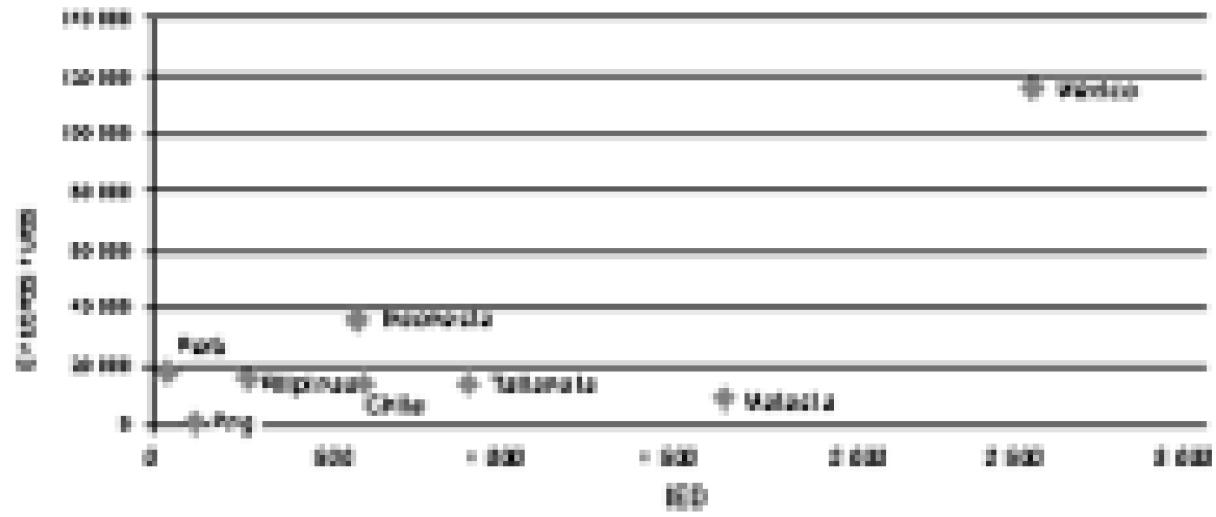

Como se ha visto anteriormente, se ha encontrado que la IED causa un efecto positivo directo e indirecto positivo en los países menos desarrollados del APEC; por lo tanto, se procederá a describir algunas medidas de política necesarias para que los países puedan atraer más IED.

Si bien la IED puede ser atraída mediante la aplicación de subsidios, esto puede ocasionar que las firmas extranjeras se apropien de todos los beneficios asociados con su inversión. Es necesario, por lo tanto, distinguir entre estrategias de política e incentivos agresivos, ya que el modo en el que la IED es atraída repercute en la forma como la sociedad como un todo puede ser beneficiada o no beneficiada.

Por eso se considera que los países se pueden hacer más atractivos mediante la educación de su fuerza laboral o mediante la mejora de la infraestructura o de sus instituciones. Sin embargo, se debe tener en cuenta que ciertos países pueden recibir grandes cantidades de IED no tanto 
por sus buenas políticas, sino por su tamaño.

- Calidad de la fuerza laboral y mejora de la infraestructura. Los países en desarrollo deben empezar a invertir en mayor medida en el entrenamiento de su fuerza laboral, así como en la mejora de la infraestructura, ya que éste es un factor importante en la atracción de la IED. Según un análisis de Barro y Lee (2000), las firmas extranjeras pueden localizarse dependiendo de la habilidad de los trabajadores: la educación de la fuerza laboral tiene un efecto positivo de IED y, por ejemplo, de acuerdo con los resultados obtenidos en los que tal variable es significativa, la población mayor de 25 años con algún estudio postsecundario ocasiona un incremento de la IED de alrededor de $3 \%$. Con respecto a la calidad y mejora de la infraestructura, se encontraron altas correlaciones entre la disponibilidad y calidad de servicios de infraestructura y la IED.

Asimismo, como se mencionó anteriormente, para poder tener un mejor aprovechamiento de los flujos de IED, los países deben contar con cierto grado de capital humano, y esto implica que la fuerza laboral debe estar entrenada y capacitada para adecuarse a un nuevo escenario. Además, los beneficios de educar a la fuerza laboral pueden afectar el tipo de IED que el país recibirá, y para un tipo de inversión dada, los países receptores podrán derivar de mejor manera los beneficios obtenidos si su fuerza laboral es educada. Es decir, los países con una fuerza laboral no entrenada atraerán IED para las industrias primarias que aprovecharán la mano de obra barata, mientras que los países con trabajadores más educados pueden atraer IED en industrias más avanzadas y se puede generar un efecto de retroalimentación mayor.

- Calidad de las instituciones. Es importante que los países cuenten con instituciones sólidas que sean capaces de dar seguridad al inversionista, que el marco legal sea adecuado, que se respeten los derechos de propiedad, que exista transparencia en los organismos en los cuales los negocios se circunscriben. Es sabido que la regulación excesiva, la corrupción o la inestabilidad política pueden desalentar a los inversionistas, mientras que un marco legal adecuado, el compromiso del gobierno de respetar sus acuerdos y tratados y la competencia de las instituciones pueden alentar o atraer al inversionista a determinado país.

Las instituciones son importantes debido a dos razones: pueden reducir el costo de hacer negocios y, más allá del efecto esperado, incrementar la predictibilidad de las reglas de política en medio de las cuales se conducen las firmas. Los factores antes mencionados, como la inestabilidad política entre otros, afectan la credibilidad del gobierno y, por lo tanto, la predictibilidad de sus acciones. Por ejemplo, mencionaremos el caso del estudio realizado por Kaufman y Lobatón (1999), quienes calculan indicadores de gobernabilidad para explorar el rol de las variables institucionales como determinantes de la ubicación de la IED. Ellos hallaron que las instituciones sí importan, y que los efectos de dichos indicadores son positivos y además grandes. De ellos, el mayor es el marco regulatorio. 


\section{Referencias bibliográficas}

AITKEN, Brian y otros. 1999. Spillovers, Foreign Investment and Export Behavior. Journal of International Economics. Vol. 43, págs. 103-132.

BARRO, Robert y LEE, Jong-Wha. 2000. International Data on Educational Attainment: Updates and Implications. NBER, Working Paper 7911. Cambridge: National Bureau of Economic Research.

BARRO, Robert y SALA-I-MARTIN, Xavier. 1995. Economic Growth. New York: McGraw-Hill.

BOREINSZTEIN, E y otros. 1998. How Does Foreign Investment Affect Economic Growth? Journal of International Economics. Vol. 45, págs. 115-135.

CHENG, Leonard y FAI LEUNG, Siu. 1999. Aspects Of Market Integration in APEC: Trade, Foreign Direct Investment and Labor Migration.

DE GREGORIO, José. 1992. Economic Growth in Latin America. Journal of Development Economics. Vol. 39, págs. 59-84.

DE MELLO, Luis. 1999. Foreign Direct Investment - Led Growth: Evidence From Time Series and Panel Data. Oxford Economic Papers. Vol. 51, págs. 133-151.

- 1997. Foreign Direct Investment in Developing Countries and Growth: A Selective Survey. Journal of Development Studies. Vol. 34, págs. 1-34.

HONG, Yoo Soo. 2000. Measures for Promoting Knowledge-based Economies in the
APEC Region. Korea institute for International Economic Policy. APEC Studies Series 00-05.

IMF. 2000. International Financial Statistics. IMF.

ISLAM, Nazrul. 1995. Growth Empirics: A Panel Data Approach. Quarterly Journal of Economics. Vol. 110, págs. 1127-1270.

KAUFFMAN y LOBATON. 1999. Governance Matters. Policy Research Working Paper 2196. Washington: Banco Mundial.

SALA-I-MARTIN, Xavier. 2000. Apuntes de crecimiento económico. Barcelona: A. Bosch Editor, 2000.

STEIN, Ernesto. 2001. Foreign Investment Policies. Chapter 18. En: Competitiveness: The Business of Growth. BID.

STEIN, Ernesto y DAUDE, Christian. 2001. Institutions, Integration and the Location of Foreign Direct Investment. Preparado para el Seminario «Towards Competitiveness: The Institutional Path». Santiago de Chile.

SUMMERS, Robert y HESTON, Alan. 1992. The Penn World Table (mark 5): An Expanded Set of International Comparisons, 1950-1988. Quarterly Journal of Economics, págs. 327-368.

UNCTAD. 2001. World Investment Report 2001: Promoting Linkages. Ginebra: United Nations. 
2000. World Investment Report 2000: Cross-border Mergers and Acquisitions and Development. Ginebra: United Nations.

1999. World Investment Report 1999: Foreign Investment and the Challenge of Development. Ginebra: United Nations.

\section{UNITED NATIONS. 1992. The Determinants} of Foreign Direct Investment: A survey Evidence. New York: United Nations Centre of Transnational Corporations; United Nations, págs. 1-80. 


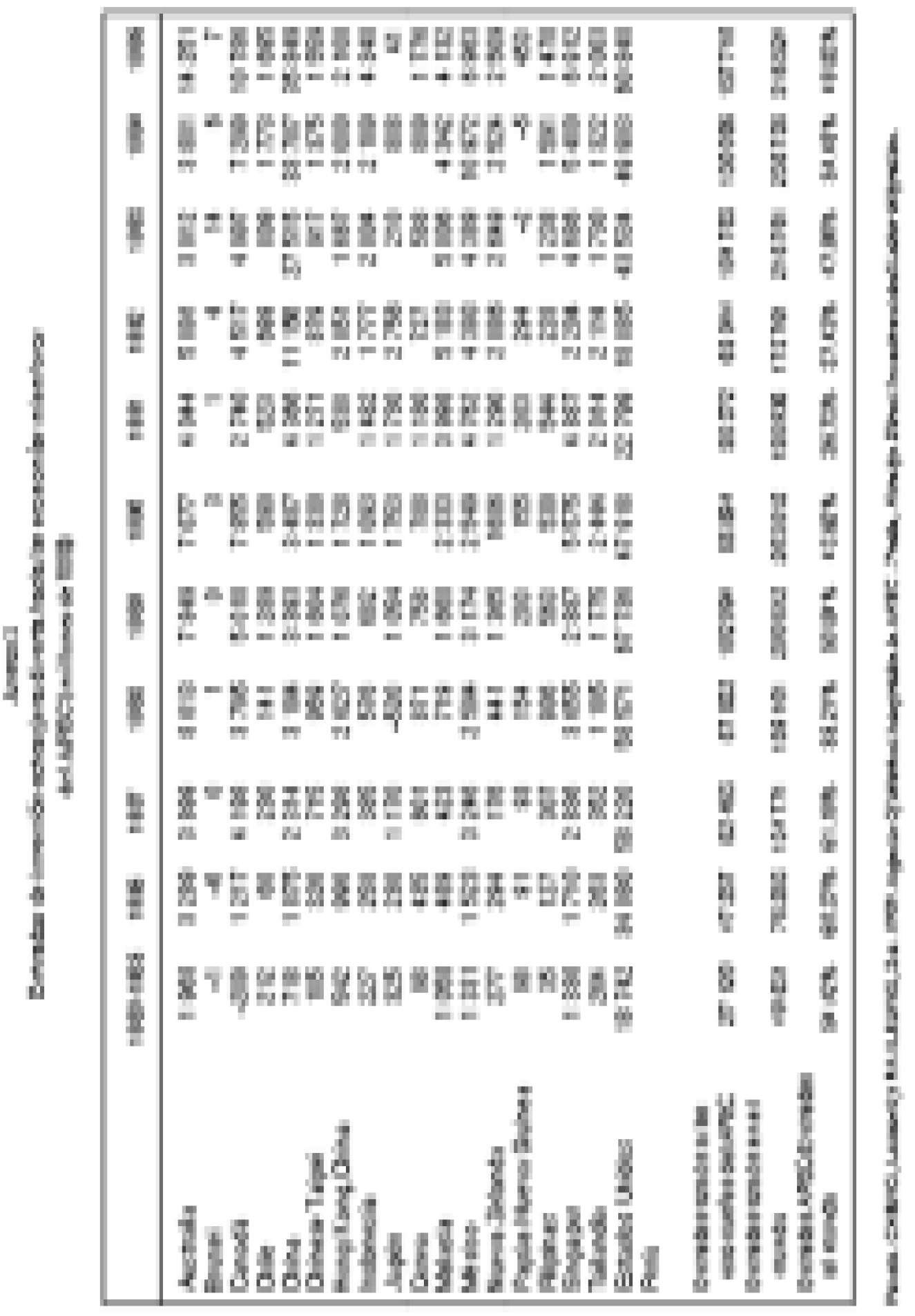


Anexo 2

Estimaciones 1980-2000

Dependent variable: GDPUS?

Method: GLS (Cross Section Weights)

Date: 03/04/02 Time: 17:43

Sample: 19802000

Included observations: 21

Total panel (balanced) observations 168

\begin{tabular}{|c|c|c|c|c|}
\hline Variable & Coefficient & Std. Error & t-Statistic & Prob. \\
\hline IED? & 4.710984 & 0.823432 & 5.721157 & 0.0000 \\
\hline GFK? & 2.593631 & 0.148888 & 17.42005 & 0.0000 \\
\hline \multicolumn{5}{|l|}{ Fixed Effects } \\
\hline TAI-C & 5105.276 & & & \\
\hline PER-C & 16615.52 & & & \\
\hline PNG-C & 2731.628 & & & \\
\hline MEX-C & 123832.1 & & & \\
\hline MAL-C & -4435.633 & & & \\
\hline CHL-C & 9079.903 & & & \\
\hline FIL-C & 20293.28 & & & \\
\hline IND-C & 39991.21 & & & \\
\hline \multicolumn{5}{|l|}{ Weighted Statistics } \\
\hline R-squared & 0.904326 & \multirow{4}{*}{\multicolumn{2}{|c|}{$\begin{array}{l}\text { Mean dependent var } \\
\text { S.D. dependent var } \\
\text { Sum squared resid }\end{array}$}} & 87079.71 \\
\hline Adjusted R-squared & 0.898876 & & & 56962.51 \\
\hline S.E. of regression & 18114.08 & & & \\
\hline & & & & $5.18 \mathrm{E}+10$ \\
\hline Log likelihood & -1738.773 & \multicolumn{2}{|c|}{ F-statistic } & 1493.437 \\
\hline Durbin-Watson stat & 0.836944 & \multicolumn{2}{|c|}{ Prob(F-statistic) } & 0.000000 \\
\hline \multicolumn{5}{|l|}{ Unweight Statistics } \\
\hline R-squared & 0.957988 & \multirow{3}{*}{\multicolumn{2}{|c|}{$\begin{array}{l}\text { Mean dependent var } \\
\text { S.D. dependent var } \\
\text { Sum squared resid }\end{array}$}} & 85924.40 \\
\hline Adjusted R-squared & 0.955595 & & & 97239.15 \\
\hline S.E. of regression & 20490.61 & & & \\
\hline Durbin-Watson stat & 0.768919 & & & \\
\hline
\end{tabular}


Dependent variable: GDPUS?

Method: GLS (Cross Section Weights)

Date: 03/04/02 Time: 17:46

Sample: 19802000

Included observations: 21

Total panel (balanced) observations 168

\begin{tabular}{|c|c|c|c|c|}
\hline Variable & Coefficient & Std. Error & t-Statistic & Prob. \\
\hline IED? & 4.324538 & 0.689845 & 6.268850 & 0.0000 \\
\hline GFK? & 2.164394 & 0.125985 & 17.17975 & 0.0000 \\
\hline KHT? & 0.019636 & 0.002695 & 7.287249 & 0.0000 \\
\hline \multicolumn{5}{|l|}{ Fixed Effects } \\
\hline TAI-C & 10115.63 & & & \\
\hline PER-C & 12027.69 & & & \\
\hline PNG-C & 2878.351 & & & \\
\hline MEX-C & 118571.7 & & & \\
\hline MAL-C & -2195.668 & & & \\
\hline CHL-C & 9079.903 & & & \\
\hline FIL-C & 2593.616 & & & \\
\hline IND-C & 9305.232 & & & \\
\hline \multicolumn{5}{|l|}{ Weighted Statistics } \\
\hline R-squared & 0.931936 & \multirow{4}{*}{\multicolumn{2}{|c|}{$\begin{array}{l}\text { Mean dependent var } \\
\text { S.D. dependent var } \\
\text { Sum squared resid }\end{array}$}} & 89299.72 \\
\hline Adjusted R-squared & 0.927601 & & & 59114.72 \\
\hline S.E. of regression & 18114.08 & & & \\
\hline & & & & $3.97 E+10$ \\
\hline Log likelihood & -1719.039 & \multicolumn{2}{|c|}{ F-statistic } & 1074.831 \\
\hline Durbin-Watson stat & 1.050717 & \multicolumn{2}{|c|}{ Prob(F-statistic) } & 0.000000 \\
\hline \multicolumn{5}{|l|}{ Unweight Statistics } \\
\hline R-squared & 0.962453 & \multirow{3}{*}{\multicolumn{2}{|c|}{$\begin{array}{l}\text { Mean dependent var } \\
\text { S.D. dependent var } \\
\text { Sum squared resid }\end{array}$}} & 85924.40 \\
\hline Adjusted R-squared & 0.960062 & & & 97239.15 \\
\hline S.E. of regression & 19432.75 & & & \\
\hline Durbin-Watson stat & 0.838753 & & & $5.93 \mathrm{E}+10$ \\
\hline
\end{tabular}


Dependent variable: GDPUS?

Method: GLS (Cross Section Weights)

Date: 03/04/02 Time: 17:47

Sample: 19802000

Included observations: 21

Total panel (balanced) observations 168

\begin{tabular}{|c|c|c|c|c|}
\hline Variable & Coefficient & Std. Error & t-Statistic & Prob. \\
\hline IED? & 2.306506 & 0.611539 & 3.77539 & 0.0002 \\
\hline GFK? & 2.203448 & 0.122322 & 18.01349 & 0.0000 \\
\hline KHT? & 0.018191 & 0.002944 & 6.178627 & 0.0000 \\
\hline IED?*KHT? & $1.87 \mathrm{E}-06$ & $5.63 \mathrm{E}-07$ & 3.324611 & 0.0011 \\
\hline \multicolumn{5}{|l|}{ Fixed Effects } \\
\hline TAI-C & 11678.04 & & & \\
\hline PER-C & 13195.02 & & & \\
\hline PNG-C & 3129.556 & & & \\
\hline MEX-C & 110050.1 & & & \\
\hline MAL-C & 983.7846 & & & \\
\hline $\mathrm{CHL}-\mathrm{C}$ & 10512.72 & & & \\
\hline FIL-C & 3335.260 & & & \\
\hline IND-C & 8623.291 & & & \\
\hline \multicolumn{5}{|l|}{ Weighted Statistics } \\
\hline R-squared & 0.935726 & \multirow{4}{*}{\multicolumn{2}{|c|}{$\begin{array}{l}\text { Mean dependent var } \\
\text { S.D. dependent var } \\
\text { Sum squared resid }\end{array}$}} & 97086.49 \\
\hline Adjusted R-squared & 0.931194 & & & 61221.81 \\
\hline S.E. of regression & 16059.07 & & & \\
\hline & & & & $4.02 \mathrm{E}+10$ \\
\hline Log likelihood & -1724.097 & \multicolumn{2}{|c|}{ F-statistic } & 757.0338 \\
\hline Durbin-Watson stat & 1.059494 & \multicolumn{2}{|c|}{ Prob(F-statistic) } & 0.000000 \\
\hline \multicolumn{5}{|l|}{ Unweight Statistics } \\
\hline R-squared & 0.969149 & \multirow{3}{*}{\multicolumn{2}{|c|}{$\begin{array}{l}\text { Mean dependent var } \\
\text { S.D. dependent var } \\
\text { Sum squared resid }\end{array}$}} & 85924.40 \\
\hline Adjusted R-squared & 0.966974 & & & 97239.15 \\
\hline S.E. of regression & 17671.30 & & & \\
\hline Durbin-Watson stat & 0981375 & & & $4.87 E+10$ \\
\hline
\end{tabular}




\section{Estimaciones 1980-1992}

Dependent variable: GDPUS?

Method: GLS (Cross Section Weights)

Date: 03/04/02 Time: 17:54

Sample: 19802000

Included observations: 13

Total panel (balanced) observations 104

Convergence achieved after 18 iteration(s)

\begin{tabular}{|c|c|c|c|c|}
\hline Variable & Coefficient & Std. Error & t-Statistic & Prob. \\
\hline IED? & 0.382026 & 0.889177 & 0.429639 & 0.6683 \\
\hline GFK? & 2.192745 & 0.109019 & 20.11347 & 0.0000 \\
\hline \multicolumn{5}{|l|}{ Fixed Effects } \\
\hline TAI-C & 14994.51 & & & \\
\hline PER-C & 20121.31 & & & \\
\hline PNG-C & 1054.269 & & & \\
\hline MEX-C & 120698.0 & & & \\
\hline MAL-C & 10120.19 & & & \\
\hline CHL-C & 15534.44 & & & \\
\hline FIL-C & 21150.55 & & & \\
\hline IND-C & 44532.15 & & & \\
\hline \multicolumn{5}{|l|}{ Weighted Statistics } \\
\hline R-squared & 0.967906 & \multirow{4}{*}{\multicolumn{2}{|c|}{$\begin{array}{l}\text { Mean dependent var } \\
\text { S.D. dependent var } \\
\text { Sum squared resid }\end{array}$}} & 101315.5 \\
\hline Adjusted R-squared & 0.964833 & & & 59276.23 \\
\hline S.E. of regression & 18114.08 & & & \\
\hline & & & & $1.16 \mathrm{E}+10$ \\
\hline Log likelihood & -946.2670 & \multicolumn{2}{|c|}{ F-statistic } & 2834.874 \\
\hline Durbin-Watson stat & 0.646668 & \multicolumn{2}{|c|}{ Prob(F-statistic) } & 0.000000 \\
\hline \multicolumn{5}{|l|}{ Unweight Statistics } \\
\hline R-squared & 0.973114 & \multirow{3}{*}{\multicolumn{2}{|c|}{$\begin{array}{l}\text { Mean dependent var } \\
\text { S.D. dependent var } \\
\text { Sum squared resid }\end{array}$}} & 61005.61 \\
\hline Adjusted R-squared & 0.970540 & & & 64765.77 \\
\hline S.E. of regression & 20490.61 & & & \\
\hline Durbin-Watson stat & 0.622721 & & & $1.16 \mathrm{E}+10$ \\
\hline
\end{tabular}


Dependent variable: GDPUS?

Method: GLS (Cross Section Weights)

Date: 03/04/02 Time: 17:52

Sample: 19801992

Included observations: 13

Total panel (balanced) observations 104

Convergence achieved after 10 iteration(s)

\begin{tabular}{|c|c|c|c|c|}
\hline Variable & Coefficient & Std. Error & t-Statistic & Prob. \\
\hline IED? & 0.478463 & 0.815822 & 0.586479 & 0.5588 \\
\hline GFK? & 2.051702 & 0.096851 & 21.18421 & 0.0000 \\
\hline KHT? & 0.008810 & 0.001826 & 4.824122 & 0.0000 \\
\hline \multicolumn{5}{|l|}{ Fixed Effects } \\
\hline TAI-C & 14522.35 & & & \\
\hline PER-C & 17783.68 & & & \\
\hline PNG-C & 975.8990 & & & \\
\hline MEX-C & 115887.8 & & & \\
\hline MAL-C & 9174.998 & & & \\
\hline $\mathrm{CHL}-\mathrm{C}$ & 13716.68 & & & \\
\hline FIL-C & 14347.52 & & & \\
\hline IND-C & 34013.11 & & & \\
\hline \multicolumn{5}{|l|}{ Weighted Statistics } \\
\hline R-squared & 0.978340 & \multirow{3}{*}{\multicolumn{2}{|c|}{$\begin{array}{l}\text { Mean dependent var } \\
\text { S.D. dependent var } \\
\text { Sum squared resid }\end{array}$}} & 108526.0 \\
\hline Adjusted R-squared & 0.976011 & & & 67927.90 \\
\hline S.E. of regression & 10520.87 & & & \\
\hline & & \multirow{2}{*}{\multicolumn{2}{|c|}{ F-statistic }} & $\begin{array}{l}1.03 E+10 \\
2100342\end{array}$ \\
\hline $\begin{array}{l}\text { Log likelihood } \\
\text { Durbin-Watson stat }\end{array}$ & $\begin{array}{r}-939.7119 \\
0.838296\end{array}$ & & & $\begin{array}{l}2100.342 \\
0.000000\end{array}$ \\
\hline \multicolumn{5}{|l|}{ Unweight Statistics } \\
\hline R-squared & 0.976171 & \multirow{3}{*}{\multicolumn{2}{|c|}{$\begin{array}{l}\text { Mean dependent var } \\
\text { S.D. dependent var } \\
\text { Sum squared resid }\end{array}$}} & 61005.61 \\
\hline Adjusted R-squared & 0.973609 & & & 64765.77 \\
\hline S.E. of regression & 10521.35 & & & \\
\hline Durbin-Watson stat & 0.711402 & & & \\
\hline
\end{tabular}


Dependent variable: GDPUS?

Method: GLS (Cross Section Weights)

Date: 03/04/02 Time: 17:55

Sample: 19801992

Included observations: 13

Total panel (balanced) observations 104

Convergence achieved after 21 iteration(s)

\begin{tabular}{|c|c|c|c|c|}
\hline Variable & Coefficient & Std. Error & t-Statistic & Prob. \\
\hline IED? & 0.095674 & 1.064247 & 0.089898 & 0.9285 \\
\hline GFK? & 2.053032 & 0.098218 & 20.90282 & 0.0000 \\
\hline KHT? & 0.006742 & 0.003960 & 1.702504 & 0.0915 \\
\hline IED?*KHT? & $1.04 \mathrm{E}-06$ & 2.03E-06 & 0.514890 & 0.6077 \\
\hline \multicolumn{5}{|l|}{ Fixed Effects } \\
\hline TAI-C & 15229.42 & & & \\
\hline PER-C & 18451.55 & & & \\
\hline PNG-C & 1051.426 & & & \\
\hline MEX-C & 115882.5 & & & \\
\hline MAL-C & 9827.500 & & & \\
\hline CHL-C & 14325.96 & & & \\
\hline FIL-C & 16013.69 & & & \\
\hline IND-C & 36136.23 & & & \\
\hline \multicolumn{5}{|l|}{ Weighted Statistics } \\
\hline R-squared & 0.978699 & \multirow{3}{*}{\multicolumn{2}{|c|}{$\begin{array}{l}\text { Mean dependent var } \\
\text { S.D. dependent var } \\
\text { Sum squared resid }\end{array}$}} & 104578.8 \\
\hline Adjusted R-squared & 0.976152 & & & 65892.78 \\
\hline S.E. of regression & 10175.73 & & & \\
\hline Log likelihood & -937.3024 & \multicolumn{2}{|c|}{ F-statistic } & $\begin{array}{l}9.53 E+09 \\
1408.995\end{array}$ \\
\hline Durbin-Watson stat & 0.825079 & \multicolumn{2}{|c|}{ Prob(F-statistic) } & 0.000000 \\
\hline \multicolumn{5}{|l|}{ Unweight Statistics } \\
\hline R-squared & 0.977951 & \multirow{3}{*}{\multicolumn{2}{|c|}{$\begin{array}{l}\text { Mean dependent var } \\
\text { S.D. dependent var } \\
\text { Sum squared resid }\end{array}$}} & 61005.61 \\
\hline Adjusted R-squared & 0.975314 & & & 64765.77 \\
\hline S.E. of regression & 10175.78 & & & \\
\hline Durbin-Watson stat & 0.750792 & & & \\
\hline
\end{tabular}




\section{Estimación 1992-2000}

Dependent variable: GDPUS?

Method: GLS (Cross Section Weights)

Date: 03/04/02 Time: 17:42

Sample: 19922000

Included observations: 9

Total panel (balanced) observations 72

\begin{tabular}{|c|c|c|c|c|}
\hline Variable & Coefficient & Std. Error & t-Statistic & Prob. \\
\hline IED? & 2.312241 & 0.781768 & 2.957709 & 0.0041 \\
\hline GFK? & 1.982678 & 0.226499 & 8.753592 & 0.0000 \\
\hline \multicolumn{5}{|l|}{ Fixed Effects } \\
\hline TAI-C & 41164.05 & & & \\
\hline PER-C & 25217.46 & & & \\
\hline PNG-C & 7524.465 & & & \\
\hline MEX-C & 235427.1 & & & \\
\hline MAL-C & 16535.82 & & & \\
\hline CHL-C & 24569.47 & & & \\
\hline FIL-C & 37646.42 & & & \\
\hline IND-C & 79738.32 & & & \\
\hline \multicolumn{5}{|l|}{ Weighted Statistics } \\
\hline R-squared & 0.907868 & \multirow{4}{*}{\multicolumn{2}{|c|}{$\begin{array}{l}\text { Mean dependent var } \\
\text { S.D. dependent var } \\
\text { Sum squared resid }\end{array}$}} & 136350.0 \\
\hline Adjusted R-squared & 0.894494 & & & 56921.59 \\
\hline S.E. of regression & 18489.13 & & & \\
\hline & & & & $2.12 \mathrm{E}+10$ \\
\hline Log likelihood & -708.4234 & \multicolumn{2}{|c|}{ F-statistic } & 610.9446 \\
\hline Durbin-Watson stat & 1.372195 & \multicolumn{2}{|c|}{ Prob(F-statistic) } & 0.000000 \\
\hline \multicolumn{5}{|l|}{ Unweight Statistics } \\
\hline R-squared & 0.974482 & \multicolumn{2}{|c|}{ Mean dependent var } & 123191.4 \\
\hline Adjusted R-squared & 0.970778 & \multirow{2}{*}{\multicolumn{2}{|c|}{$\begin{array}{l}\text { S.D. dependent var } \\
\text { Sum squared resid }\end{array}$}} & 122218.7 \\
\hline S.E. of regression & 20892.66 & & & \\
\hline Durbin-Watson stat & 1.683605 & & & \\
\hline
\end{tabular}


Dependent variable: GDPUS?

Method: GLS (Cross Section Weights)

Date: 03/04/02 Time: 17:46

Sample: 19922000

Included observations: 9

Total panel (balanced) observations 72

\begin{tabular}{rcccc}
\hline Variable & Coefficient & Std. Error & t-Statistic & Prob. \\
\hline IED? & 2.128968 & 0.712575 & 2.987710 & 0.0038 \\
GFK? & 1.808157 & 0.200941 & 8.998465 & 0.0000 \\
KHT? & 0.032346 & 0.007154 & 4.521694 & 0.0000
\end{tabular}

Fixed Effects

TAI-C $\quad 33271.83$

PER-C $\quad 11807.47$

PNG-C $\quad 7152.598$

MEX-C $\quad 181963.4$

MAL-C $\quad 8869.201$

CHL-C $\quad 16996.13$

FIL-C $\quad-8796.393$

IND-C $\quad-20268.38$

Weighted Statistics

\begin{tabular}{|c|c|c|c|}
\hline R-squared & 0.927817 & Mean dependent var & 142921.2 \\
\hline Adjusted R-squared & 0.915983 & S.D. dependent var & 58934.63 \\
\hline S.E. of regression & 17082.56 & Sum squared resid & \\
\hline Log likelihood & -705.7184 & F-statistic & 392.0358 \\
\hline Durbin-Watson stat & 1.793289 & Prob(F-statistic) & 0.000000 \\
\hline \multicolumn{4}{|l|}{ Unweight Statistics } \\
\hline R-squared & 0.976062 & Mean dependent var & 123191.4 \\
\hline Adjusted R-squared & 0.972138 & S.D. dependent var & 122218.7 \\
\hline S.E. of regression & 20892.66 & Sum squared resid & \\
\hline Durbin-Watson stat & 1.857099 & & $2.54 \mathrm{E}+10$ \\
\hline
\end{tabular}


Dependent variable: GDPUS?

Method: GLS (Cross Section Weights)

Date: 03/04/02 Time: 17:49

Sample: 19922000

Included observations: 9

Total panel (balanced) observations 72

\begin{tabular}{|c|c|c|c|c|}
\hline Variable & Coefficient & Std. Error & t-Statistic & Prob. \\
\hline IED? & 1.274593 & 0.662736 & 1.923230 & 0.0582 \\
\hline GFK? & 1.768380 & 0.196455 & 9.001471 & 0.0000 \\
\hline KHT? & 0.032488 & 0.006912 & 4.700159 & 0.0000 \\
\hline IED?*KHT? & $1.06 \mathrm{E}-06$ & $6.31 \mathrm{E}-07$ & 1.682608 & 0.0966 \\
\hline \multicolumn{5}{|l|}{ Fixed Effects } \\
\hline TAI-C & 35956.02 & & & \\
\hline PER-C & 12734.13 & & & \\
\hline PNG-C & 7353.298 & & & \\
\hline MEX-C & 170522.7 & & & \\
\hline MAL-C & 11686.15 & & & \\
\hline $\mathrm{CHL}-\mathrm{C}$ & 19433.94 & & & \\
\hline FIL-C & -9530.812 & & & \\
\hline IND-C & -22510.73 & & & \\
\hline \multicolumn{5}{|l|}{ Weighted Statistics } \\
\hline R-squared & 0.951138 & \multirow{3}{*}{\multicolumn{2}{|c|}{$\begin{array}{l}\text { Mean dependent var } \\
\text { S.D. dependent var } \\
\text { Sum squared resid }\end{array}$}} & 161325.3 \\
\hline Adjusted R-squared & 0.942180 & & & 73139.46 \\
\hline S.E. of regression & 17586.94 & & & \\
\hline Log likelihood & -706.2055 & \multicolumn{2}{|c|}{ F-statistic } & $\begin{array}{l}1.86 \mathrm{E}+10 \\
389.3170\end{array}$ \\
\hline Durbin-Watson stat & 1.783359 & \multicolumn{2}{|c|}{ Prob(F-statistic) } & 0.000000 \\
\hline \multicolumn{5}{|l|}{ Unweight Statistics } \\
\hline R-squared & 0.978142 & \multirow{4}{*}{\multicolumn{2}{|c|}{$\begin{array}{l}\text { Mean dependent var } \\
\text { S.D. dependent var } \\
\text { Sum squared resid }\end{array}$}} & 123191.4 \\
\hline Adjusted R-squared & 0.974135 & & & 122218.7 \\
\hline S.E. of regression & 19655.93 & & & \\
\hline & & & & $2.32 \mathrm{E}+10$ \\
\hline Durbin-Watson stat & 1.928826 & & & \\
\hline
\end{tabular}

